\title{
Multiparameter Radar Observations of Time Evolution of Convective Storms: Evaluation of Water Budgets and Latent Heating Rates
}

\author{
Hui TONG \\ University of Colorado at Boulder, Boulder, Colorado \\ V. CHANDRASEKAR \\ Colorado State University, Fort Collins, Colorado \\ K. R. KNUPP AND JAmes StalkeR \\ Earth System Science Laboratory, University of Alabama in Huntsville, Huntsville, Alabama
}

(Manuscript received 7 August 1997, in final form 7 November 1997)

ABSTRACT

\begin{abstract}
One advantage of dual-polarization radars is the ability to differentiate between water and ice phases in storms. The application of difference reflectivity $\left(Z_{\mathrm{DP}}\right)$ in the analysis of mixed-phase precipitation is presented. Here, $Z_{\mathrm{DP}}$ analysis is used to obtain the fraction of water and ice in mixed-phase precipitation. The techniques developed are applied to data collected on 9 August 1991 during the Convection and Precipitation Electrification experiment. Time series of storm total liquid and ice water contents are computed. The liquid and ice water contents are used in a water budget equation to obtain the net latent heating of the convective storm. It is shown that the latent heating profile shows good correlation with the updraft and electric field increases in the time evolution of the storm.
\end{abstract}

\section{Introduction}

Multiparameter radar is a very useful tool for studying the microphysics of storms. Polarization diversity parameters such as differential reflectivity $\left(Z_{\mathrm{DR}}\right)$ and specific differential propagation phase $\left(K_{\mathrm{DP}}\right)$ have been used by researchers to identify and study water to ice transition regions in convective storms (Aydin et al. 1986; Balakrishnan and Zrnić 1990). Golestani et al. (1989) introduced difference reflectivity $\left(Z_{\mathrm{DP}}\right)$. This parameter can be utilized to quantitatively estimate the fraction of ice and water in mixed-phase precipitation. Bringi et al. (1997) have analyzed $Z_{\mathrm{DR}}$ columns, and linear depolarization ratio signatures, to infer rapid development in mixed-phase precipitation. In this paper we present a study of the evolution of water and ice contents in a convective storm case study, including a quantitative estimation of ice and water contents in mixed-phase regions.

Sikdar et al. (1974) estimated storm total latent heating rates from radar observations using the time history of reflectivity patterns and, subsequently, estimated the water content. With the advent of multiparameter radars this process can be done more accurately. In this paper

Corresponding author address: Dr. V. Chandrasekar, Department of Electrical Engineering, Colorado State University, Fort Collins, CO 80523-1373. we present a technique to estimate storm total latent heating rates for convective storms. Our paper is organized as follows. Section 2 describes the $Z_{\mathrm{DP}}$ signal that is used to quantitatively describe the ice and water contents in mixed-phase precipitation. Section 3 describes the dataset used in this paper. Section 4 describes the estimations of the water budget and latent heating rates for a convective storm observed on 9 August 1991. The latent heat of condensation can be derived using multiple Doppler analysis. Latent heating estimates based on multiple Doppler analysis and multiparameter radar analysis are presented in section 5. Section 6 summarizes the important results of this paper.

\section{2. $Z_{\mathrm{DP}}$ analysis for rain-ice mixtures}

Dual-polarization radars measure, in addition to the conventional reflectivity, the differential reflectivity between two polarization states. Seliga and Bringi (1976) introduced $Z_{\mathrm{DR}}$ as the ratio of the power received at the horizontal and vertical polarization states as

$$
Z_{\mathrm{DR}}=10 \log \left(\frac{Z_{\mathrm{H}}}{Z_{\mathrm{V}}}\right),
$$

where $Z_{\mathrm{H}}$ and $Z_{\mathrm{V}}$ are the reflectivity factors at horizontal and vertical polarizations, respectively; $Z_{\mathrm{DR}}$ provides an additional measurement of the precipitation medium and 
is a relative measurement (ratio of powers) conventionally expressed in decibels.

Golestani et al. (1989) defined an alternate form of differential reflectivity called difference reflectivity $\left(Z_{\mathrm{DP}}\right)$ defined as

$$
Z_{\mathrm{DP}}=Z_{\mathrm{H}}-Z_{\mathrm{v}},
$$

which is the difference between horizontal and vertical reflectivities. When the difference reflectivity is positive (as in the case of rain medium), it can be expressed as

$$
Z_{\mathrm{DP}}(\mathrm{dB})=10 \log \left(Z_{\mathrm{H}}-Z_{\mathrm{V}}\right) \text {. }
$$

The $Z_{\mathrm{DP}}$ parameter has some very useful properties for the analysis of rain-ice mixtures.

Consider a radar resolution volume consisting of mixtures of rain and hail particles in a convective storm. The raindrops on the average are nonspherical and oriented (Seliga and Bringi 1976), hail particles are tumbling, and, on the average, the medium appears isotropic (Aydin et al. 1986; Bringi et al. 1986a,b; Zrnić et al. 1993). Under these conditions the ice particles have nearly the same reflectivity at both horizontal and vertical polarizations. Therefore, when the radar resolution volume contains mixtures of rain and ice particles, we can write

$$
Z_{\mathrm{DP}}=10 \log \left[\sum_{\text {hail }}\left(Z_{\mathrm{H}}-Z_{\mathrm{V}}\right)+\sum_{\text {rain }}\left(Z_{\mathrm{H}}-Z_{\mathrm{V}}\right)\right] .
$$

The assumption that $Z_{\mathrm{H}}=Z_{\mathrm{V}}$ for ice particles, such as hail that tumbles, can be made. In rain, however, $Z_{\mathrm{H}} \neq$ $Z_{\mathrm{v}}$ since raindrops become more oblate in shape with increasing size; thus, their minor axis is oriented vertically with small deviations from this orientation (Balakrishnan and Zrnić 1990). When a radar resolution volume consisting of a rain-ice mixture is illuminated at horizontal and vertical polarizations, the returned signal will be greater at horizontal polarizations than in the vertical due to the rain component. This implies that $Z_{\mathrm{DP}}$ will be insensitive to the ice particles.

Let $Z_{\mathrm{H}}^{r}, Z_{\mathrm{H}}^{i}$ be the constituent reflectivity due to rain and ice particles, respectively, in a radar resolution volume that has total reflectivity $Z_{\mathrm{H}}$. By the assumption that $Z_{\mathrm{H}}^{i}=Z_{\mathrm{V}}^{i}$ in (4) we can write

$$
Z_{\mathrm{H}}-Z_{\mathrm{V}}=Z_{\mathrm{H}}^{r}-Z_{\mathrm{V}}^{r} \text {. }
$$

The variability of $Z_{\mathrm{DP}}$ versus $Z$ in a rain medium can be easily obtained based on theoretical considerations. Raindrop shapes can be approximated by oblate spheroids, and the axis ratios decrease from unity as the size increases. Ulbrich (1983) showed that the natural variations in raindrop size distribution can be adequately described by a gamma model of the form

$$
N(D)=N_{0} D^{\mu} e^{-\Lambda D}
$$

where $N(D)$ is the number of drops per unit volume per unit size interval $(D$ to $D+\Delta D), N_{0}=8 \times 10^{3} \mathrm{~m}^{-3}$ $\mathrm{mm}^{-1}$, and
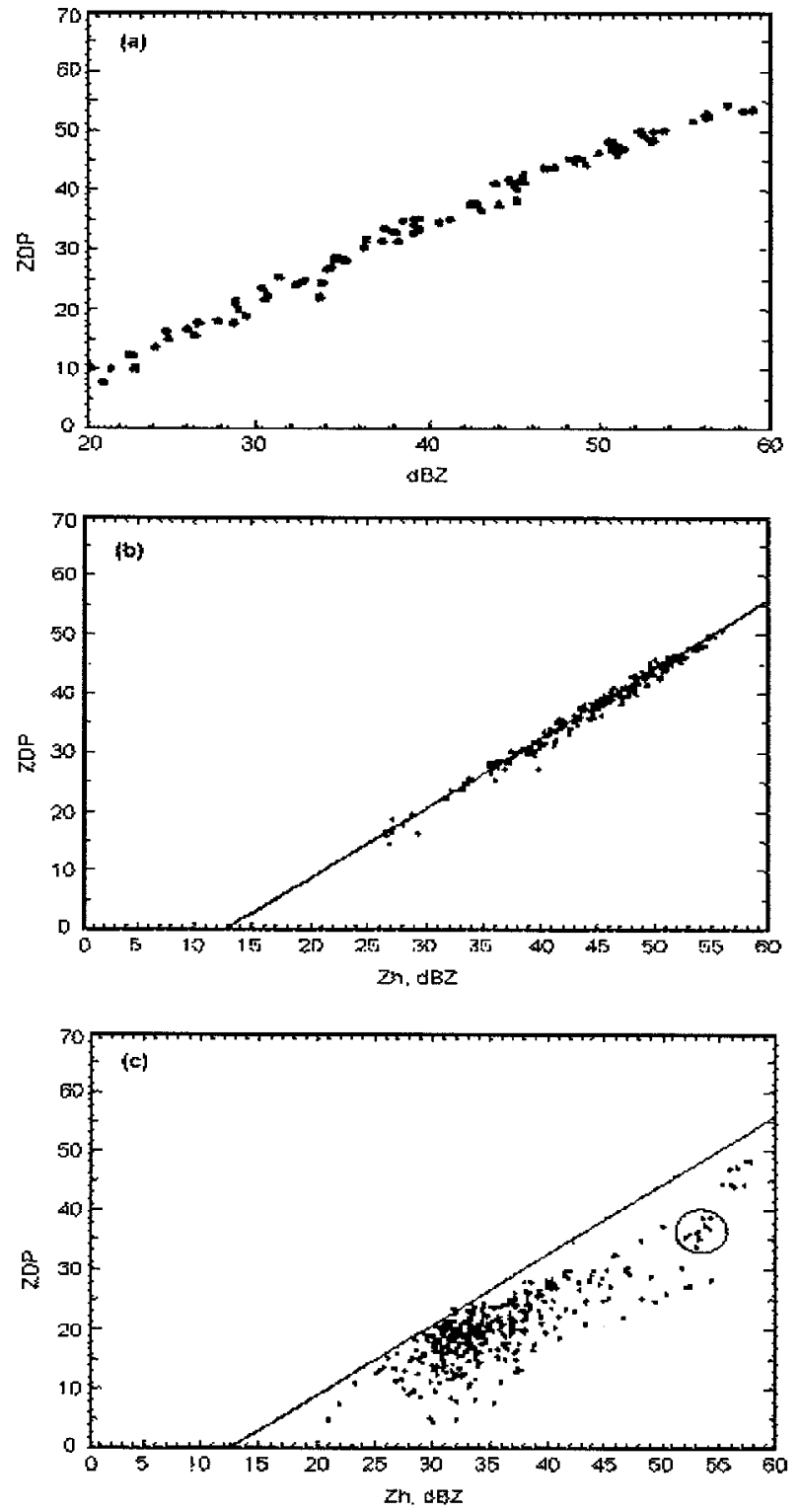

FIG. 1. Scatterplots of $Z_{\mathrm{DP}}(\mathrm{dB})$ vs $Z_{\mathrm{H}}$ : (a) several gamma raindrop size distributions, (b) data from rainfall, and (c) regions of rain-ice mixture (from Golestani et al. 1989).

$$
\Lambda=\frac{3.67+\mu}{D_{0}},
$$

where $D_{0}$ is the median volume diameter. Figure 1a shows a scattergram of $Z_{\mathrm{DP}}$ versus $Z_{\mathrm{H}}$ obtained for different raindrop size distributions. It can be seen from Fig. 1a that $Z_{\mathrm{DP}}$ versus $\mathrm{dB} Z$ is nearly a linear relationship. Figure $1 \mathrm{~b}$ shows a scatterplot of $Z_{\mathrm{DP}}$ versus $\mathrm{dBZ}$ for radar data collected in convective rainshafts. These data plots of $Z_{\mathrm{DP}}$ versus $\mathrm{dB} Z$ are in excellent agreement with the mean fit to the data of Fig. 1a. On the other hand, Fig. 1c shows $Z_{\mathrm{DP}}$ versus $\mathrm{dBZ}$ in the regions of rain mixed with ice. Note that the scatter lies below the 


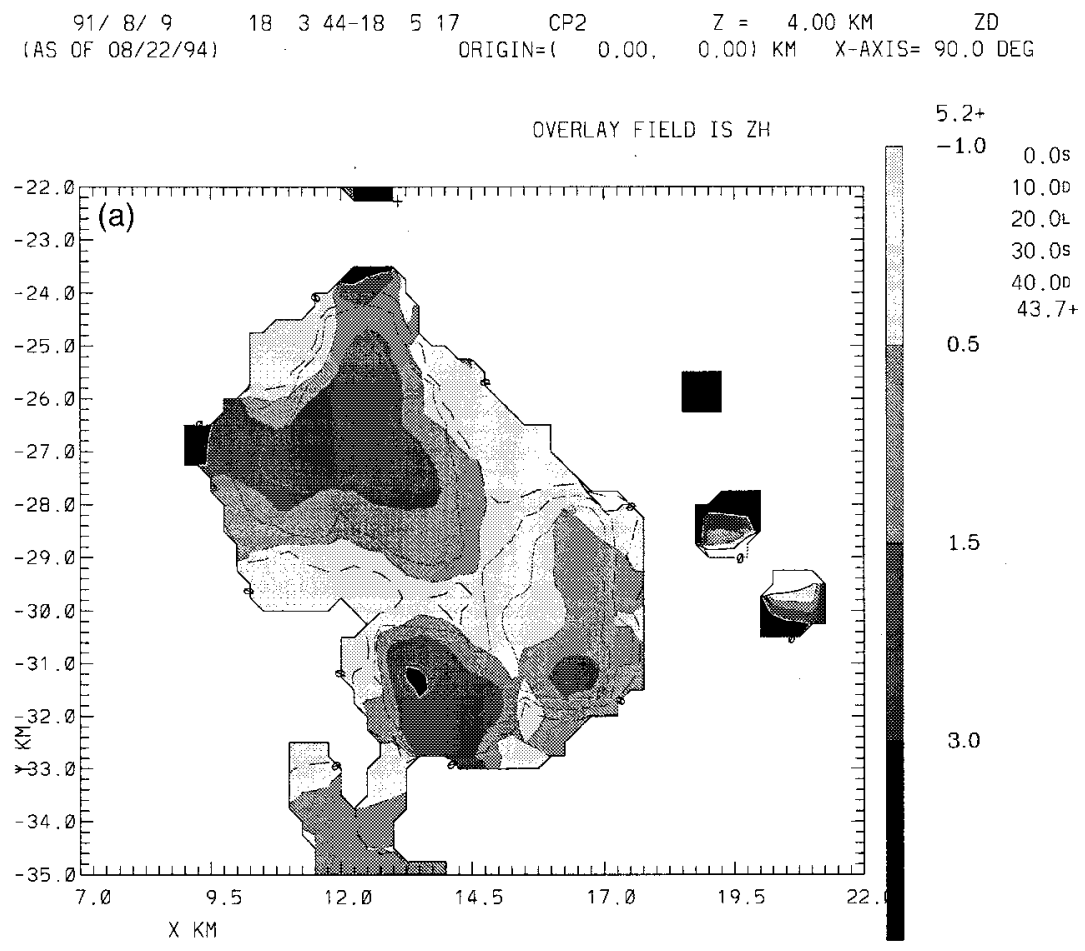

$108 / 22 / 94-16,36: 431-$ FRAME $=19$

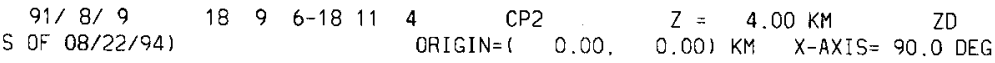

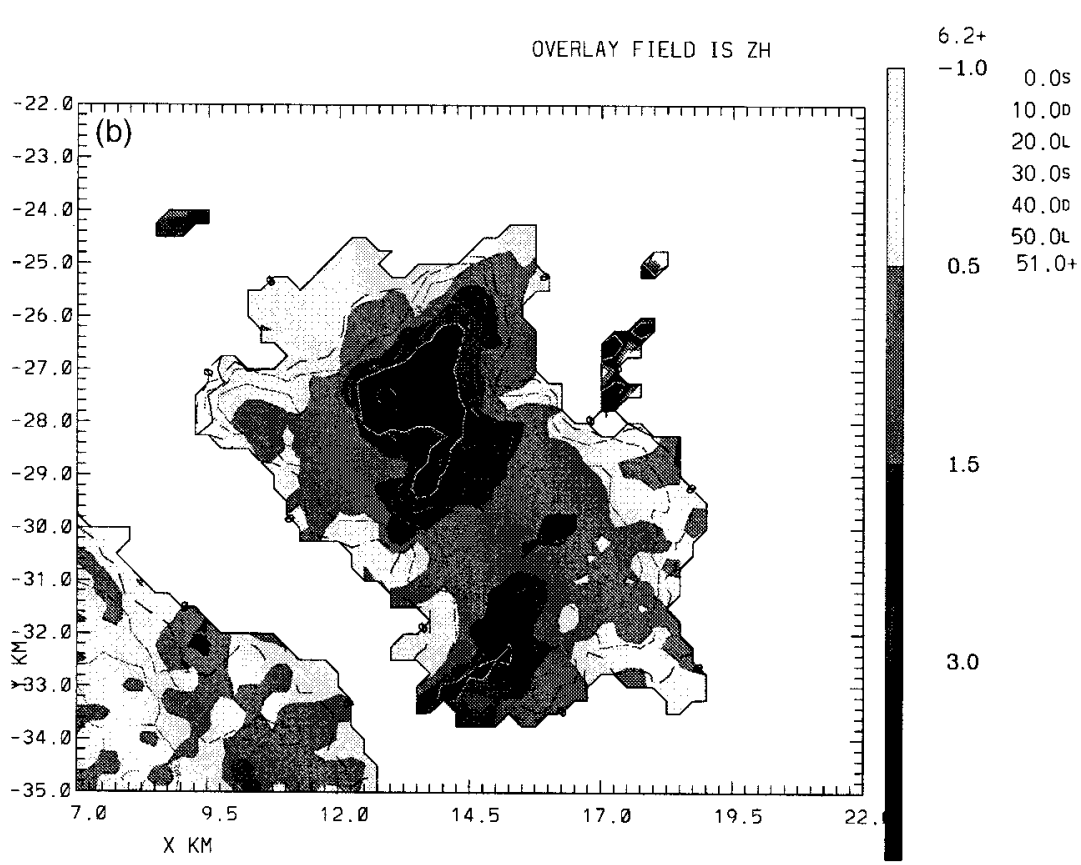

$108 / 22 / 94-16,46,531-$ FRAME $=19$

FIG. 2. (a) CAPPI at 4.0-km height of $Z_{\mathrm{H}}$ contours with $Z_{\mathrm{DR}}$ gray scales at 1803 UTC. (b) CAPPI at $4.0-\mathrm{km}$ height of $Z_{\mathrm{H}}$ contours with $Z_{\mathrm{DR}}$ gray scales at 1809 UTC. (c) CAPPI at 4.0$\mathrm{km}$ height of $Z_{\mathrm{H}}$ contours with $Z_{\mathrm{DR}}$ gray scales at $1815 \mathrm{UTC}$. 


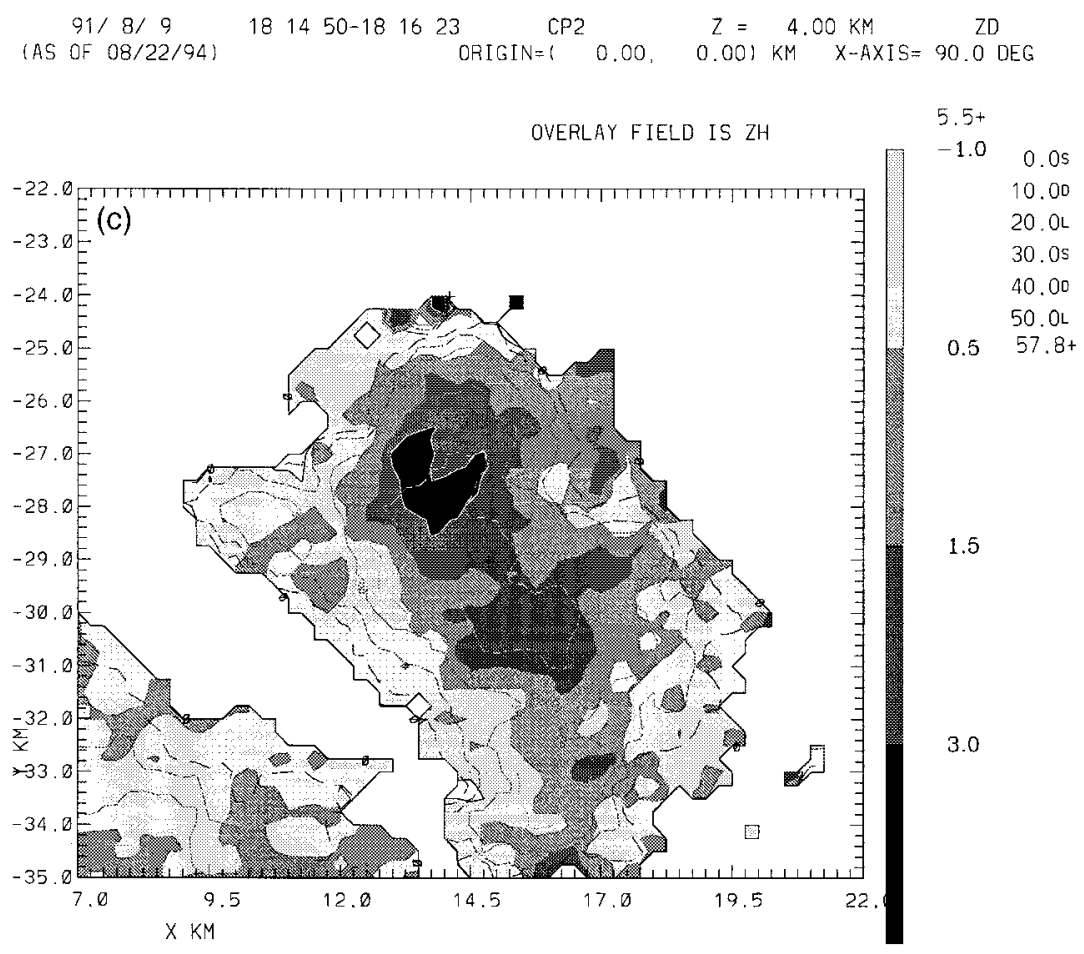

FIG. 2. (Continued)

solid straight line, or the rain line. At a given $Z_{\mathrm{DP}}$ value, the difference between $\mathrm{dBZ}$ (rain line) and $\mathrm{dBZ}$ (actual) is the deviation from the rain line in decibels.

We can calculate the fraction of ice in the rain-ice mixture in the following manner:

$$
10 \log Z_{\mathrm{H}}=10 \log Z_{\mathrm{H}}^{r}+\Delta Z
$$

and

$$
10 \log Z_{\mathrm{H}}=10 \log \left(Z_{\mathrm{H}}-Z_{\mathrm{H}}^{i}\right)+\Delta Z .
$$

The above equation can be rewritten as

$$
Z_{\mathrm{H}}=\left(Z_{\mathrm{H}}-Z_{\mathrm{H}}^{i}\right) 10^{0.1(\Delta Z)} .
$$

From (10) we can obtain the ice fraction as

$$
f=\frac{Z_{\mathrm{H}}^{i}}{Z_{\mathrm{H}}}=1-10^{-0.1(\Delta Z)},
$$

where $\Delta Z$ is the horizontal deviation of the data point (in $\mathrm{dB}$ ) from the rain line in a $Z_{\mathrm{DP}}-\mathrm{dBZ}$ scattergram and $f$ is reflectivity-weighted ice fraction.

In Fig. 1c, the deviation for the cluster of points when $Z_{\mathrm{DP}}$ is between 35 and $40 \mathrm{~dB}$ is $10 \mathrm{~dB}$ when the absolute reflectivity is between 53 and $56 \mathrm{~dB}$. The corresponding value of $f$ is 0.9 . It is important to remember that the ice fraction in this study does not refer to the fraction of ice mass or volume of ice in a mixed phase region, but it does refer to the fraction of the reflectivity signal in a volume arising from scattering by ice. The statistics of the $Z_{\mathrm{DP}}$ parameter and its correlation with $Z_{\mathrm{H}}$ are discussed in the appendix. In the following section, we utilize the $Z_{\mathrm{DP}}$-based analysis to study the microphysical evolution of a convective storm, observed during the Convection and Precipitation Electrification (CaPE) experiment.

\section{Overview of dataset used for analysis}

The dataset chosen for this study was recorded by the National Center for Atmospheric Research CP-2 radar on 9 August 1991 in Florida during CaPE. Details about CaPE can be found in Foote (1991). Characteristics of the CP-2 radar can be found in Bringi and Hendry (1990). The radar data were collected using plan position indicator volume sector scans with the angular limits and elevation steps adaptively determined by scan optimizer software.

Figures $2 \mathrm{a}-\mathrm{c}$ show the constant-altitude plan position indicators (CAPPIs) of radar data of the storm cell under consideration. The storm under study was first detected at 1748 UTC. Henceforth, all heights are above mean sea level, and time is universal time coordinated (UTC). At 1751 UTC the peak reflectivity increased to 22.5 $\mathrm{dBZ}$, and $Z_{\mathrm{DR}}$ increased to $0.75 \mathrm{~dB}$, evidence of drop formation through coalescence. About 10 min later 


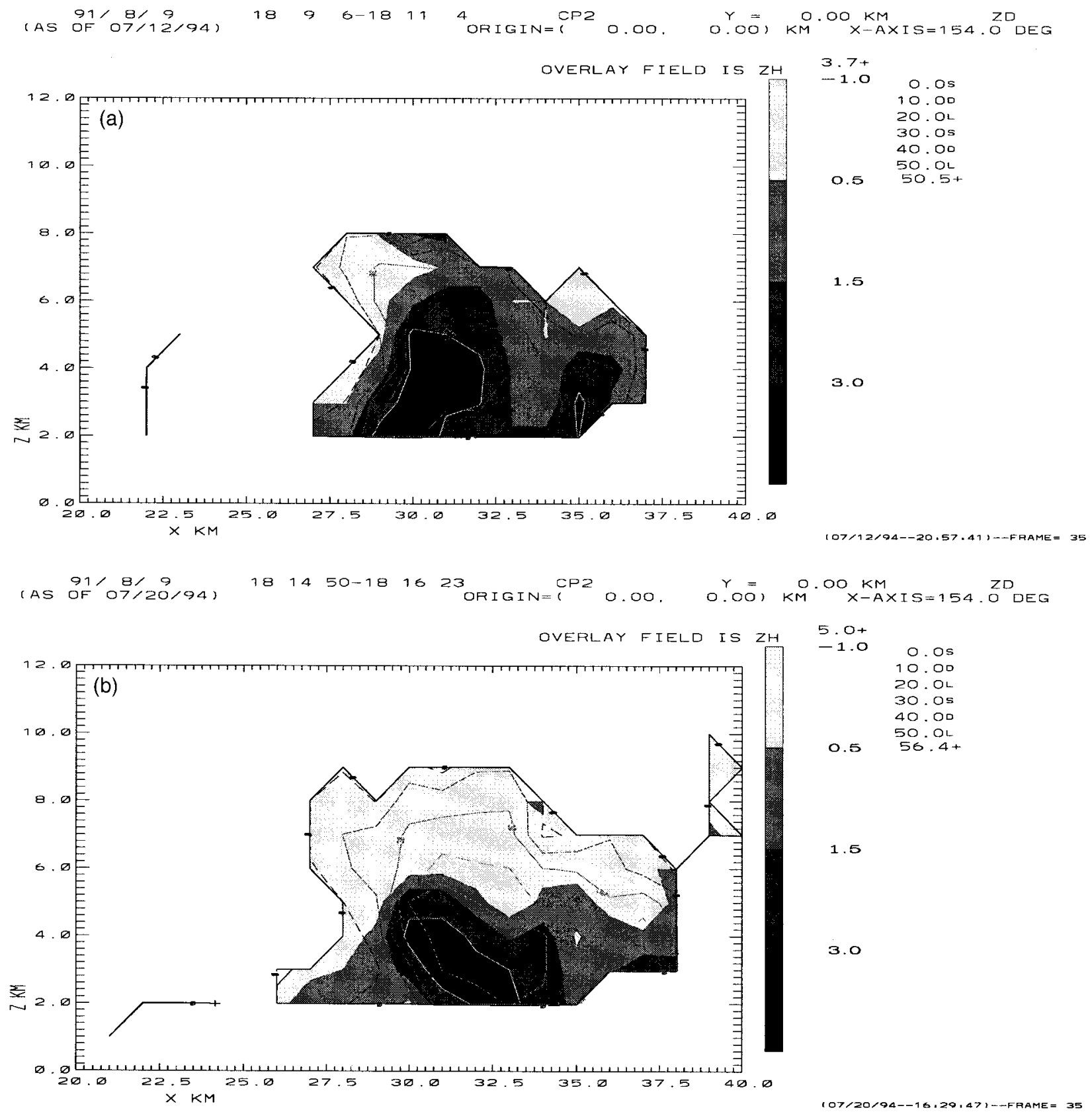

FIG. 3. (a) Vertical section along a SE-NW line in Fig. 2b at 1809 UTC. (b) Vertical section along a SE-NW line in Fig. 2c at 1815 UTC.

(1800 UTC), a highly positive $Z_{\mathrm{DR}}$ column had formed. A positive $Z_{\mathrm{DR}}$ column persisted until 1809 UTC and then glaciated, releasing latent heat, accompanied by strong vertical growth. The height of the freezing level was $4.5 \mathrm{~km}$ (Bringi et al. 1997). The cloud cell of interest was detected (1755 UTC), about $4 \mathrm{~km}$ northwest of another cell that was in a more mature phase (see the CAPPI in Fig. 2a). Both cells were about $10 \mathrm{~km}$ northeast of an intense but weakening multicell thunderstorm.
Figures $2 \mathrm{~b}$ and $2 \mathrm{c}$ show a CAPPI of the cloud cell at the $4.0-\mathrm{km}$ height at 1809 and 1815 UTC, respectively. Contours of $Z_{\mathrm{H}}$ start at $0 \mathrm{dBZ}$ and increase by $10 \mathrm{~dB}$, while $Z_{\mathrm{DR}}$ is shown as a grayscale with darker shades representing larger $Z_{\mathrm{DR}}$. The cell is centered at $X=13, Y=-27 \mathrm{~km}$ in Fig. 2b, which also shows the positive $Z_{\mathrm{DR}}$ column. In Fig. $2 \mathrm{c}$ the strength of the column has weakened considerably. Figures $3 \mathrm{a}$ and $3 \mathrm{~b}$ show a vertical cross section along a line oriented southeast-northwest in Figs. $2 b$ and 2c, respectively. The pos- 
itive $Z_{\mathrm{DR}}$ column in Fig. 3a is clearly visible at 1809 UTC, while at 1812 UTC the cloud has glaciated. At 1815 UTC, the reflectivity core was descending and the $Z_{\mathrm{DR}}$ structure conforms to the more usual ice particles melting to drops situation.

\section{Radar estimates of the water budget and latent heating rates}

\section{a. Ice fractions}

We have described the method of calculating ice fractions using the parameter $Z_{\mathrm{DP}}$ in section 2. Once the fraction of the reflectivity signal due to ice is known, the mass of ice can then be estimated from an empirical relationship relating $Z_{\mathrm{H}}^{\mathrm{i}}$ to ice water content (IWC).

First, we obtain an expression relating $Z_{\mathrm{DP}}$ to $Z$ in a region of only rain. In this manner a rain line may be obtained for this particular dataset. To do this, regression analysis was done in the pure rain regions of the storm for each radar volume scan. Pure rain regions are defined as those regions containing all liquid hydrometeors. In this analysis, the altitude of the pure rain regions are chosen to be about $2 \mathrm{~km}$. This height is well below the melting layer (about $4.5 \mathrm{~km}$ ) but high enough to avoid the ground clutter in the radar measurements and to contain $Z_{\mathrm{DR}}$ values above $0 \mathrm{~dB}$. Figure 4 shows the scatterplot of $Z_{\mathrm{DP}}$ versus $Z$ from radar data at a height of $2.5 \mathrm{~km}$. Figure 4 also shows the regression line of the data. The data were thresholded at $20 \mathrm{dBZ}$ to avoid gradient errors caused by partial filling of the radar resolution volume at low reflectivities. To find the fraction of $Z$ contributed by ice at a given radar resolution volume, we compute the deviation of a measured $Z-Z_{\mathrm{DP}}$ pair on the scatterplot from the rain line. As indicated in (8), a measured reflectivity value is expressed as the sum of the expected reflectivity based on the rain line plus the deviation from this line.

The ice fraction at each CAPPI grid point was computed as follows. Each observed value of $Z_{\mathrm{DP}}$ was used to calculate the corresponding rain reflectivity value from the rain line. This value was then subtracted from the observed reflectivity to give the deviation from the rain line. The fraction of reflectivity due to ice was then calculated using (11). Small negative deviations caused by the statistical fluctuations of the radar return signals were set to zero since they would result in negative ice fractions. Also, it is assumed that deviations of greater than $10 \mathrm{~dB}$ from the rain line should be interpreted as pure ice. Therefore, at grid points where $\Delta Z>10 \mathrm{~dB}$, the ice fraction was automatically set to 1.0 .

Vertical profiles of ice fraction (layer averaged) are shown in Figs. 5a and 5b. Starting at 1803 UTC the ice fraction calculations show that the storm is composed entirely of water up to $4 \mathrm{~km}$. Above this level, there is an indication that glaciation has just started, as seen in the slight increase in $f$. Further glaciation is seen at 1805 UTC. The ice fraction profiles also show that gla-

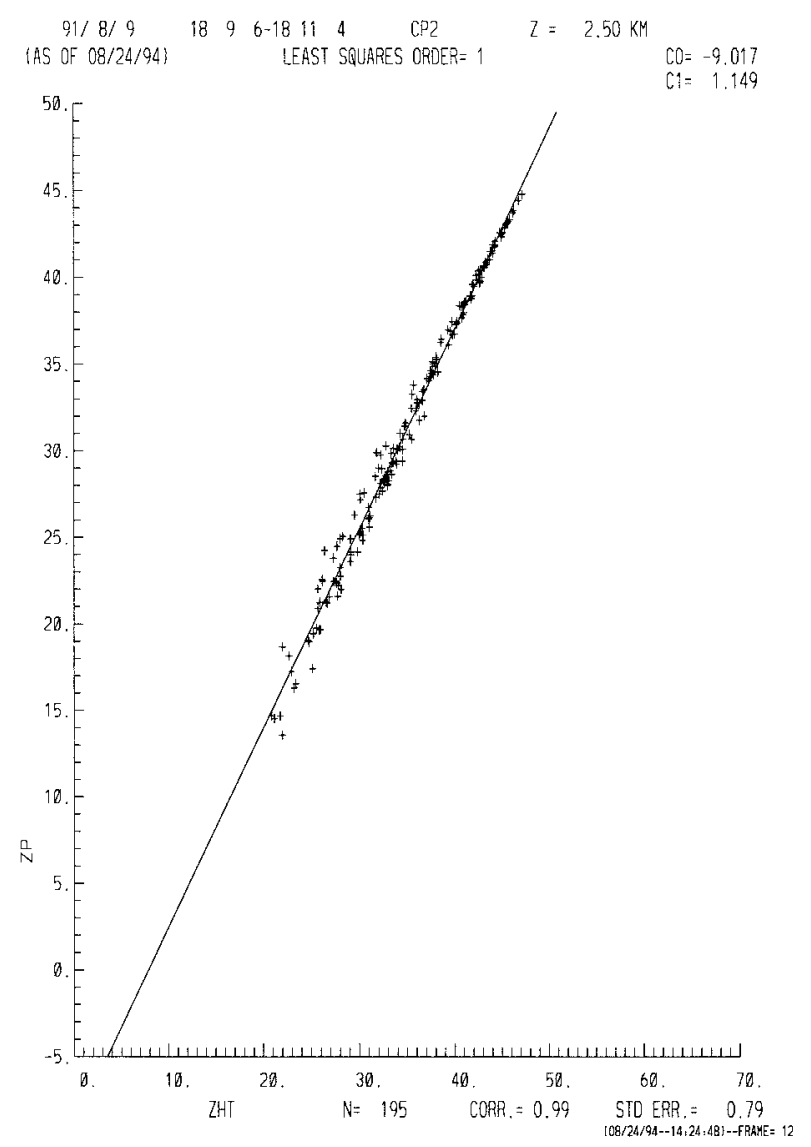

FIG. 4. Scatterplot and best-fit regression line of the S-band horizontal reflectivity $\left(Z_{\mathrm{H}}\right)$ vs $Z_{\mathrm{DP}}$ at $2.5-\mathrm{km}$ height 1809 UTC 9 Aug 1991.

ciation continues until about 1820 UTC, decreasing to an altitude of about $4 \mathrm{~km}$. Ice fractions increasing in magnitude and decreasing in altitude with time correspond to the descent of the precipitation core. Another feature evident in the ice fraction profiles is that the greatest glaciation occurs between 1809 and 1811 UTC. This time period shows not only the greatest increase in $f$ per layer but also the greatest drop in altitude of the ice fraction line. Based on this progression, one would expect a large increase in the ice content of the cell during this period. Having calculated the ice fractions, it is now possible to calculate the liquid and ice water contents of the storm.

\section{b. Liquid water content ( $L W C)$}

Since the calculation of ice fractions provides information on the reflectivity contributed by water hydrometeors, rainwater content $(M)$ can be calculated using an empirical $M-Z$ relation (Chandrasekar et al. 1991):

$$
M=3.93 \times 10^{-3} Z_{\mathrm{H}}^{r 0.549},
$$

where $M$ is in $\mathrm{g} \mathrm{m}^{-3}$ and $Z_{\mathrm{H}}^{r}$ is in $\mathrm{mm}^{6} \mathrm{~m}^{-3}$ at each grid point. Here, $Z_{\mathrm{H}}^{r}$ was calculated by multiplying $Z_{\mathrm{H}}$ by 

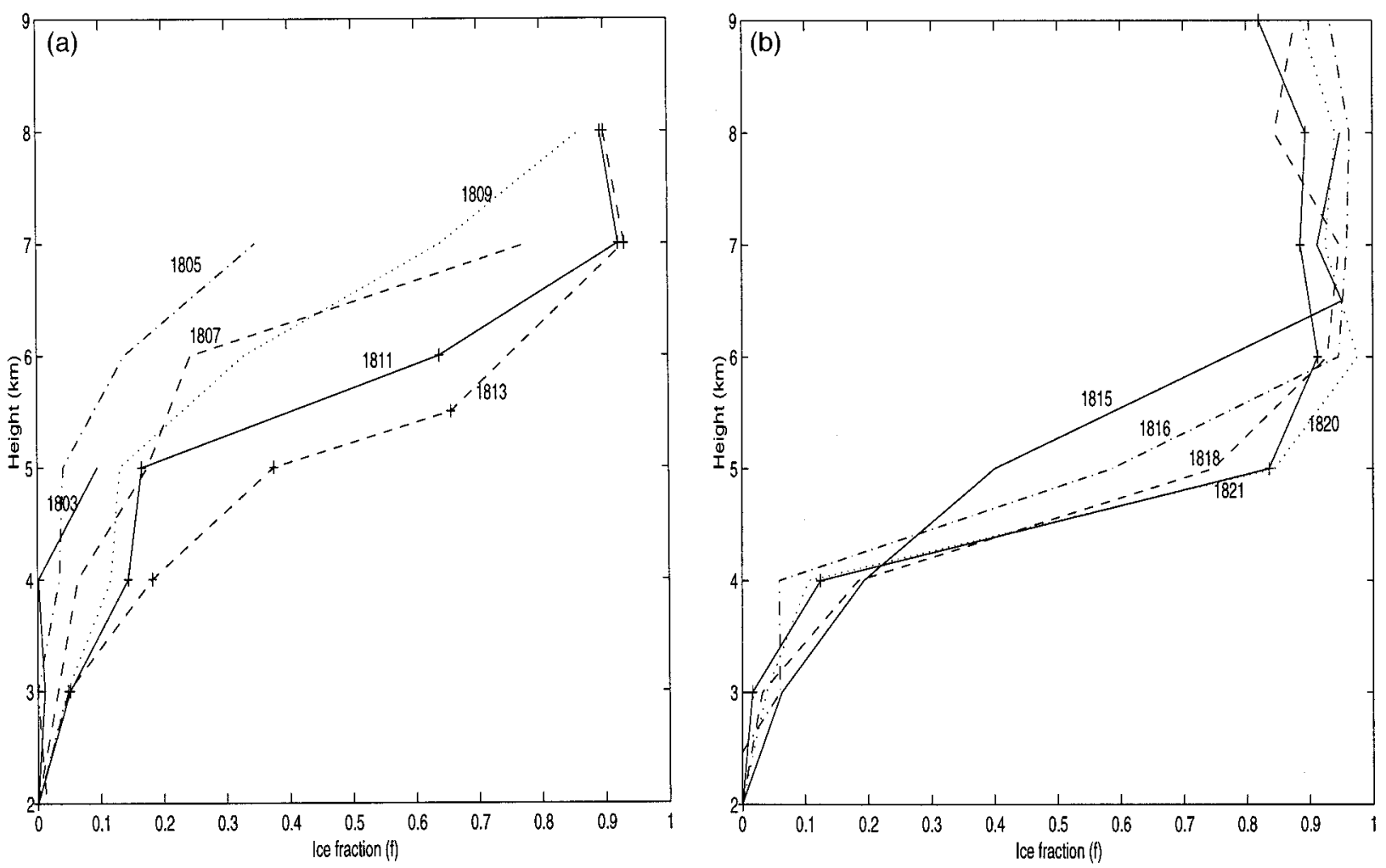

FIG. 5. (a) Vertical profiles of the average ice fraction $(f)$ from 1803 to about 1813 UTC 9 Aug 1991. (b) Vertical profiles of the average ice fraction $(f)$ from 1815 to about 1821 UTC 9 Aug 1991.

$1-f$ for mixed-phase regions. Vertical profiles of layertotal LWC for each time interval are shown in Figs. 6a and 6b. From 1803 to 1813 UTC the LWC increases, although the level of maximum LWC decreases due to glaciation taking place at higher levels and the overall decent of the precipitation core. Starting at 1813 UTC and continuing throughout the life cycle of the storm, the peak liquid water content is detected at $3.5 \mathrm{~km}$.

\section{c. Ice water content (IWC)}

Calculation of ice water content is more difficult. The lack of information regarding typical ice particle densities, aggregation behaviors, and their scattering properties makes the task of defining an empirical $I-Z$ relation (where $I$ denotes IWC) difficult. In general, $I-Z$ relations exhibit more variability than $M-Z$ relations since ice particle density may not be the same for all particles. For this study, a first-order approximation of the IWC is made. The first difference between ice and water scatters to correct for in the reflectivity signal is the index of refraction. If two hydrometeors, identical in every aspect with the exception of one being ice and the other water, are illuminated by a radar beam, the backscattering cross section for the ice hydrometeors will be only a fraction of that for the water hydrometeors. To obtain the corrected reflectivity signal in an ice region, accounting for the difference in the index of refraction, the correction is a simple addition of a few decibels to the reflectivity signal in ice regions, where the actual added value depends on the density. The factor $\left|K_{\text {ice }}\right|^{2}$ that is responsible for this change in reflectivity factor can be approximated (based on regression fit) as

$$
\left|K_{\text {ice }}\right|^{2}=0.2152 \rho^{2.01},
$$

where $\rho$ is the density of ice. A second correction deals with the density of ice particles. Depending on particle type, ice hydrometeor densities can range from $0.1 \mathrm{~g}$ $\mathrm{cm}^{-3}$ for aggregates of dendritic crystals to about $0.9 \mathrm{~g}$ $\mathrm{cm}^{-3}$ for hailstones. Considering the rapid glaciation of the storms studied here, we assume that the primary ice nucleation mechanism was contact freezing of supercooled raindrops, where existing ice particles are the freezing nuclei. Therefore, the ice particles on average can be represented as graupel having a density of about $0.4 \mathrm{~g} \mathrm{~cm}^{-3}$. The presence of graupel particles was also confirmed by aircraft observations (Bringi et al. 1997). With these two corrections, IWCs were calculated as follows. The reflectivity factor due to ice can be expressed as

$$
Z_{\text {ice }}=Z_{m} f \frac{\left|K_{w}\right|^{2}}{\left|K_{\text {ice }}\right|^{2}},
$$

where $\left|K_{w}\right|^{2}$ is 0.933 (for water), $Z_{m}$ is the reflectivity factor measured by the radar, and $f$ is the ice fraction. The IWC is subsequently estimated as 

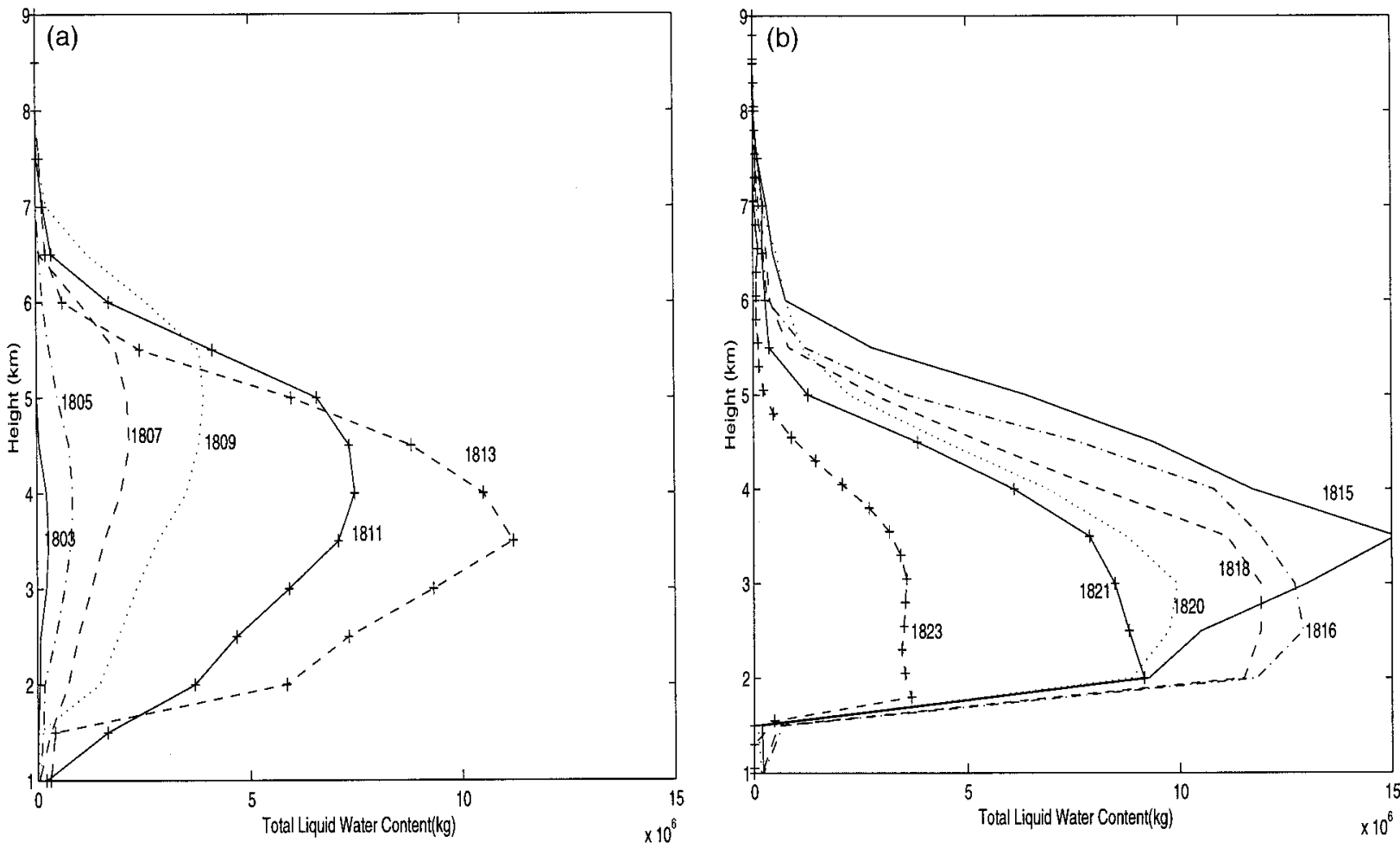

FIG. 6. (a) Vertical profiles of layer-total liquid water contents from 1803 to about 1813 UTC 9 Aug 1991. (b) Vertical profiles of layertotal liquid water contents from 1815 to about 1823 UTC 9 Aug 1991.

$$
I=3.93 \times 10^{-3} Z_{\mathrm{ice}}^{0.549} \rho,
$$

where $Z_{\text {ice }}$ is obtained from (13). Assuming a density of $0.4 \mathrm{~g} \mathrm{~cm}^{-3}$ for graupel, the vertical profiles for IWCs are shown in Figs. 7a and 7b. At 1803 UTC there is virtually no ice present. From 1807 UTC, glaciation begins at $5 \mathrm{~km}$ and above and continues as IWC increases through 1816 UTC. As anticipated, the increase in IWC during this time period is accompanied by a descent in the level at which ice is present. The peak IWC appears to be at $5 \mathrm{~km}$, whereas the peak LWC was at $3.5 \mathrm{~km}$.

\section{d. Rainfall rate}

Rainfall is a sink for the storm total LWC. To include as much of the effects of evaporation in the overall latent heating budgets as possible, the rainfall rate, $R$, should be computed at a level close to the ground, where rates of evaporation are typically highest. However, to avoid ground clutter contamination in calculations, $R$ is computed at $2 \mathrm{~km}$ above the ground.

The rainfall rate is defined as the mass flux of raindrops falling through a unit horizontal area per unit time,

$$
R=\frac{\pi}{6} \int_{0}^{D_{m}} V_{t}(D) N(D) D^{3} d D,
$$

where $D$ is the drop diameter, $N(D)$ is the raindrop size distribution, $D_{m}$ is the maximum drop diameter, and
$V_{t}(D)$ is the terminal velocity of raindrops. Three commonly used rainfall algorithms are $R\left(Z_{\mathrm{H}}\right), R\left(Z_{\mathrm{H}}, Z_{\mathrm{DR}}\right)$, and $R\left(K_{\mathrm{DP}}\right)$, respectively, where

$$
R\left(Z_{\mathrm{H}}\right)=0.036 Z_{\mathrm{H}}^{0.625},
$$

where $R$ is in $\mathrm{mm} \mathrm{h}^{-1}$ and $Z_{\mathrm{H}}$ is in $\mathrm{mm}^{6} \mathrm{~m}^{-3}$ (one of many $Z-R$ relations);

$$
R\left(Z_{\mathrm{H}}, Z_{\mathrm{DR}}\right)=1.9539 \times 10^{-3} Z_{\mathrm{H}}^{0.97} Z_{\mathrm{DR}}^{-1.05},
$$

where $Z_{\mathrm{H}}$ is in $\mathrm{mm}^{6} \mathrm{~m}^{-3}$ and $Z_{\mathrm{DR}}$ is in $\mathrm{dB}$ (Gorgucci et al. 1994); and

$$
R\left(K_{\mathrm{DP}}\right)=36.912 K_{\mathrm{DP}}
$$

(Sachidananda and Zrnić 1985; Gorgucci et al. 1994).

In this study, rainfall rate is estimated using (17) and (18). Our dataset does not have $K_{\mathrm{DP}}$ measurements; however, the CP-2 radar also has simultaneous X-band measurements. We utilize X-band attenuation $A_{X}$ measurements because $A_{X}$ is approximately related to $K_{\mathrm{DP}}$ by $K_{\mathrm{DP}} \approx 1.25 A_{X}$ (Bringi et al. 1990). Subsequently, the $\mathrm{X}$-band specific attenuation was used to estimate rainfall. Equation (18) is modified

$$
R\left(A_{X}\right)=46.14 A_{X} .
$$

Therefore, when $A_{X}>0.5$, (19) was used; when $A_{X}<$ 0.5 , (17) was used. 

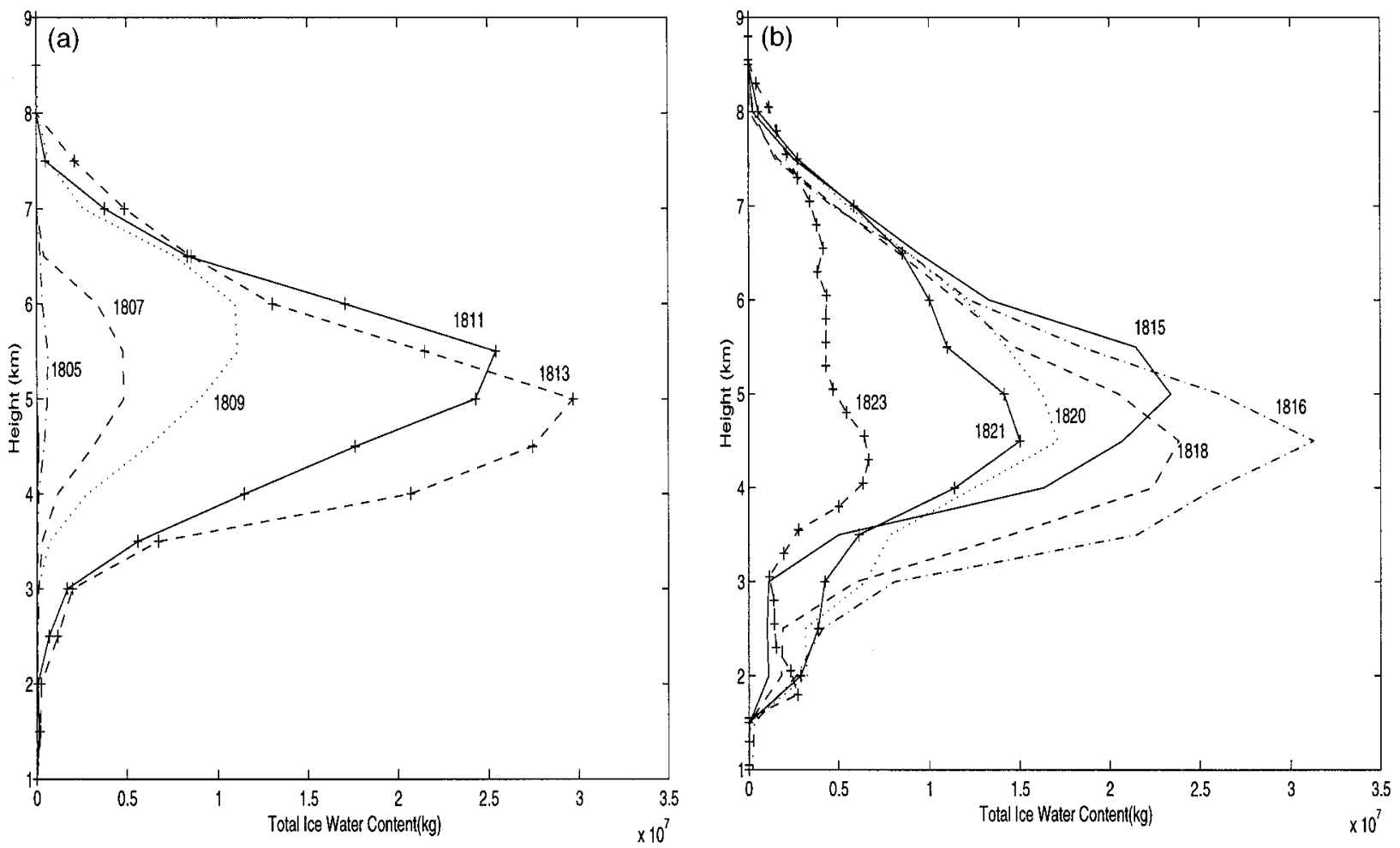

FIG. 7. (a) Vertical profiles of layer-total ice water contents from 1803 to about 1813 UTC 9 Aug 1991. (b) Vertical profiles of layer-total ice water contents from 1815 to about 1823 UTC 9 Aug 1991.

\section{e. Latent heating estimates}

The time profile of storm total liquid and ice water contents can be utilized in a water budget equation using a procedure similar to that proposed by Sikdar et al. (1974).

The water and ice budget for the storm can be written as

$$
d M / d t=C-E-R-F+\mathrm{Me}
$$

and

$$
d I / d t=F-\mathrm{Me},
$$

where $d M / d t$ is the time rate of change of total liquid water content, $d I / d t$ is the time rate of change of total ice water content, $C$ is the condensation rate, $E$ is the evaporation rate, $F$ is the rate of freezing of liquid water to ice, Me is the rate of melting of ice to liquid water, and $R$ is the rainfall rate.

The only terms neglected in the above equations are deposition and sublimation rates. An observation of the melting layer profiles indicates that an increase in IWC occurs with a corresponding increase in $f$. This implies that IWC production is primarily a result of freezing. Potentially depositional growth can take place after glaciation. However, IWC decreases after glaciation. Therefore, we conclude that deposition and sublimation do not play a major role in the ice budget of this storm (Chandrasekar et al. 1991). Figure 8 shows the time series of storm total liquid and ice water contents for the cloud cell. Figure 9a shows three quantities derived from the radar observations: $d M / d t, d I / d t$, and $R$. As can be seen from (20) and (21), the latent heating from $C$ - $E$ can be obtained from $d M / d t, d I / d t$, and $R$ by multiplying by the latent heat of vaporization, $L_{v}=2.50$ $\times 10^{6} \mathrm{~J} \mathrm{~kg}^{-1}$. Similarly, the latent heating from $F-$ Me is $d I / d t$ times the latent heat of fusion, $L_{f}=3.34$ $\times 10^{5} \mathrm{~J} \mathrm{~kg}^{-1}$. Figure $9 \mathrm{~b}$ shows these two component latent heating rates and the total latent heating rate for the storm. The small contribution of freezing and melting to the total heating budget arises from the smaller value of $L_{f}$.

The maximum positive net latent heating occurred between 1810 and 1813 UTC (see Fig. 9b) when the storm reached its maximum vertical development. Net latent heating decreased rapidly after this and then reached another smaller positive net latent heating peak at 1817 UTC. This second peak was accompanied by an enhanced E field detected by the National Oceanic and Atmospheric Administration P-3 (Bringi et al. 1997). The maximum negative net latent heating occurred between 1818 and 1820 UTC, after that the storm latent heating rate returned to a small stable value, indicating the ending phase of this storm cell. Also, from Fig. 9b, if the curve of total latent heating rate is integrated, the total heating would be much larger than the total cooling. This is easily understood in terms of 


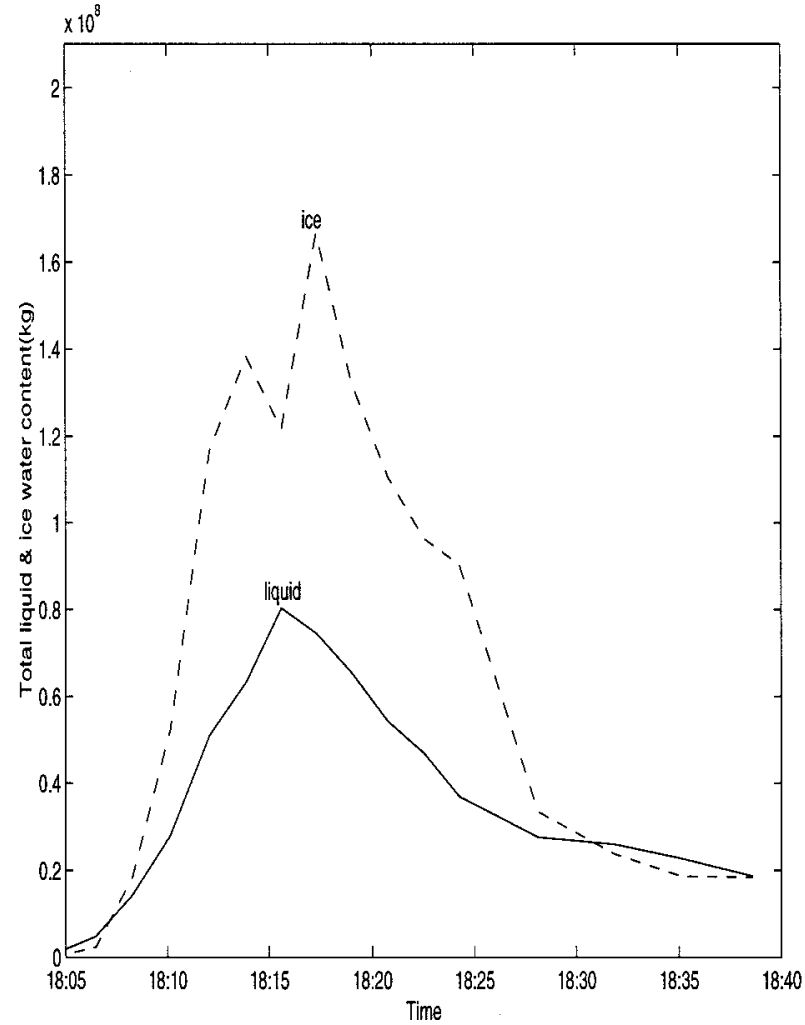

FIG. 8. Time series of storm-total liquid and ice water contents on 9 Aug 1991

the rainfall efficiency of the storm; that is, more water vapor is condensed into liquid water than is rained out of the storm, thus more latent heat is released to the environment than removed from it through evaporation.

\section{Multiple Doppler analysis}

In this section, latent heating by condensation is estimated from vertical motion fields obtained from a multiple Doppler radar analysis using three radars (see Bringi et al. 1997 for details). The results are compared to the latent heating obtained from the multiparameter radar analysis presented in the previous section. The updraft field is used to estimate latent heating as follows. Assuming the updraft is just saturated, the rate of change of cloud liquid water content $M$ can be expressed as

$$
\frac{d M}{d t}=c_{p} w(z)\left(\Gamma_{d}-\Gamma_{s}\right) / L_{v},
$$

where $c_{p}$ is the specific heat at constant pressure, $w(z)$ is vertical motion, $\Gamma_{d}$ the dry-adiabatic lapse rate (constant at $\left.-9.8 \mathrm{~K} \mathrm{~km}^{-1}\right), \Gamma_{s}$ the psuedoadiabatic lapse rate, and $L_{v}$ the latent heat of vaporization. From (22), net latent heating is found by multiplying (22) by $L_{v}$ and an elemental mass $\left[\rho_{0}(z) d x d y d z\right]$ to get

$L_{v} \frac{d M}{d t} d x d y d z \rho_{0}(z)=c_{p} \rho_{0}(z) w(z)\left(\Gamma_{d}-\Gamma_{s}\right) d x d y d z$.
Equation (23) gives the differential heating rate ( $\mathrm{J}$ $\mathrm{s}^{-1}$ ), which upon integration through the cloud volume results in the total heating due to condensation/evaporation (assuming psuedoadiabatic ascent/descent).

The total net latent heating is

$$
c_{p} \Delta x \Delta y \int_{0}^{z^{\prime}} \rho_{0}(z) w(z)\left(\Gamma_{d}-\Gamma_{s}\right) d x d y d z .
$$

The air density $\rho_{0}(z)$ is approximated from a standard atmospheric density profile and $w(z)$ is vertical motion averaged over the updraft region, defined by all grid points for which $w>1 \mathrm{~m} \mathrm{~s}^{-1}$. The psuedoadiabat $\Gamma_{s}$ is determined from the equivalent potential temperature $\left(\theta_{e}\right)$ of the inflow air, obtained from the cloud-base value from a representative sounding taken within $15 \mathrm{~km}$ of the storm at 1800 UTC. Thus, two assumptions are made in this analysis: 1) the updraft is just saturated and 2) the $\theta_{e}$ of air within the updraft is well approximated by the cloud-base value. This latter assumption implies an absence of mixing. Figure 10 shows the results from the multiple Doppler analysis. Note, in the Doppler analysis, the latent heating computations were terminated at about 1815 UTC because of the merger of the cell with adjacent cells after this time. From Fig. 10, it can be seen that multiple Doppler analysis results agree fairly well with those obtained from the multiparameter radar analysis.

\section{Summary and conclusions}

This paper presents the use of multiparameter data toward the study of mixed-phase precipitation. The $Z_{\mathrm{DP}}$ parameter is shown to be useful for quantitative analysis in mixed-phase regions of storms. The application of $Z_{\mathrm{DP}}$ is similar to that of the specific differential phase $\left(K_{\mathrm{DP}}\right)$, where $K_{\mathrm{DP}}$ is related primarily to the liquid phase of rain-hail mixtures. The primary intent of the paper was to introduce a technique for quantitatively analyzing the time evolution of convective water budgets using multiparameter radar data. Sikdar et al. (1974) used radar data to evaluate water and latent heat budgets in convective storms. With the introduction of multiparameter radars, two very significant advances have been made: 1) an estimate of the water and ice regions in a convective storm and 2) a method to quantitatively separate of rain and ice portions in a rain-ice mixture. In convective storms the mixed-phase region represents a significant portion of the storm. Therefore, accounting for rain-mixed-phase-ice transitions can significantly improve the quantitative estimates of water and ice contents.

This paper essentially presents a methodology demonstrating the application of the $Z_{\mathrm{DP}}$ parameter to study the time evolution of convective storms. The parameter $Z_{\mathrm{DP}}$ is fairly easy to measure and can be computed gate by gate for any radar measuring $Z_{\mathrm{H}}$ and $Z_{\mathrm{DR}}$. The time evolution of estimated water budgets and rainfall rates 

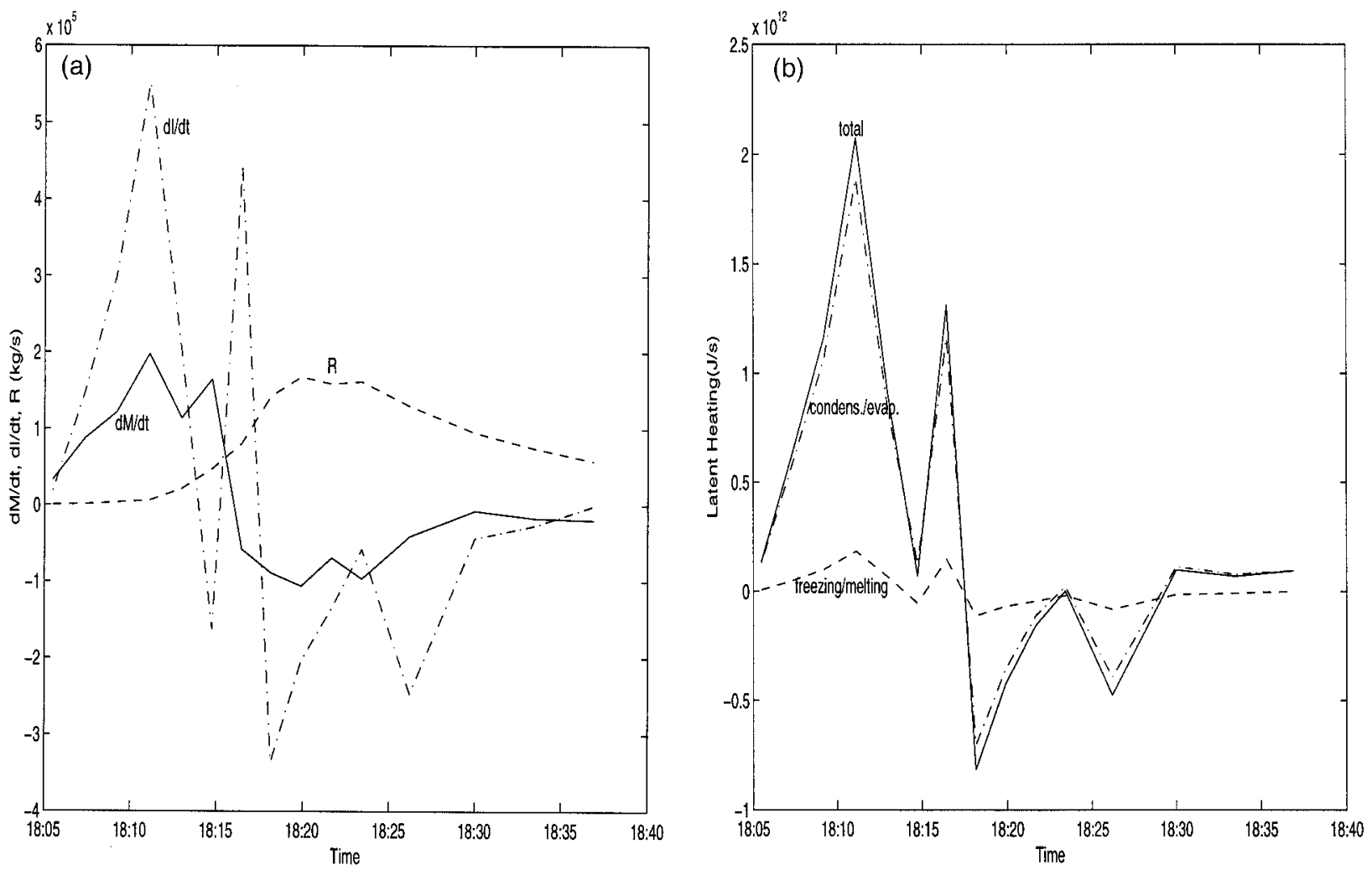

FIG. 9. (a) Time series of the time rate of change of liquid water content, $d M / d t$; ice water content, $d I / d t$; and rainfall rate, $R$, on 9 Aug 1991. (b) Time series of latent heating rates from condensation and evaporation (dash-dot line), freezing and melting (dashed line), and the net latent heat (solid line) on 9 Aug 1991.

were used to estimate the storm total latent heating rates. The latent heating estimates obtained from multiparameter radar compared fairly well with those obtained from multiple Doppler analysis. In addition, the latent heating time profile could be correlated with various microphysical and dynamic developments in the storm such as the vertical development and enhancement of electric fields. Thus, it appears that multiparameter radar data analysis using $Z_{\mathrm{DP}}$ can be very useful in quantitative analysis of convective storms.

Acknowledgments. This research was supported by the National Science Foundation, ATM-9200761 (TH and VC) and ATM-9200667 (KK and JS). The authors acknowledge helpful discussions with Professor Bringi of Colorado State University.

\section{APPENDIX}

\section{Statistical Properties of the $Z_{\mathrm{DP}}$ Signal}

A dual-polarized radar receives backscattered power at horizontal and vertical polarizations alternating between them on a pulse-to-pulse basis. Representing the power samples of echos from a given resolution volume as $P_{\mathrm{H}}$ and $P_{\mathrm{V}}$ for horizontally and vertically polarized transmissions, respectively, we obtain the mean power estimates
$\hat{P}_{\mathrm{H}}$ and $\hat{P}_{\mathrm{V}}$ by averaging $M$ samples having the same polarization:

$$
\begin{aligned}
& \hat{P}_{\mathrm{H}}=\frac{1}{M} \sum_{n=1}^{M} P_{\mathrm{H}, 2 n} \\
& \hat{P}_{\mathrm{V}}=\frac{1}{M} \sum_{n=1}^{M} P_{\mathrm{V}, 2 n+1} .
\end{aligned}
$$

The differential reflectivity $\left(Z_{\mathrm{DR}}\right)$ is expressed in decibels as

$$
Z_{\mathrm{DR}}=10 \log \left(\frac{\hat{P}_{\mathrm{H}}}{\hat{P}_{\mathrm{V}}}\right) .
$$

We define $P_{\text {diff }}$ as the difference between the powers received at horizontal and vertical polarizations:

$$
P_{\text {diff }}=\hat{P}_{\mathrm{H}}-\hat{P}_{\mathrm{V}} \text {. }
$$

The reflectivity factor $Z_{\mathrm{H}, \mathrm{V}}$ can be obtained from $\hat{P}_{\mathrm{H}, \mathrm{V}}$ through the radar constant $G$. The reflectivity estimates can typically be measured to accuracies better than 1 $\mathrm{dB}$, and $Z_{\mathrm{DR}}$ can be estimated with an accuracy of a few tenths of a decibel. In this appendix, we derive the properties of the $Z_{\mathrm{DP}}$ signal. Here $Z_{\mathrm{DP}}$ can be obtained from $P_{\text {diff }}$ as

$$
Z_{\mathrm{DP}}=G P_{\text {diff }} \cdot
$$




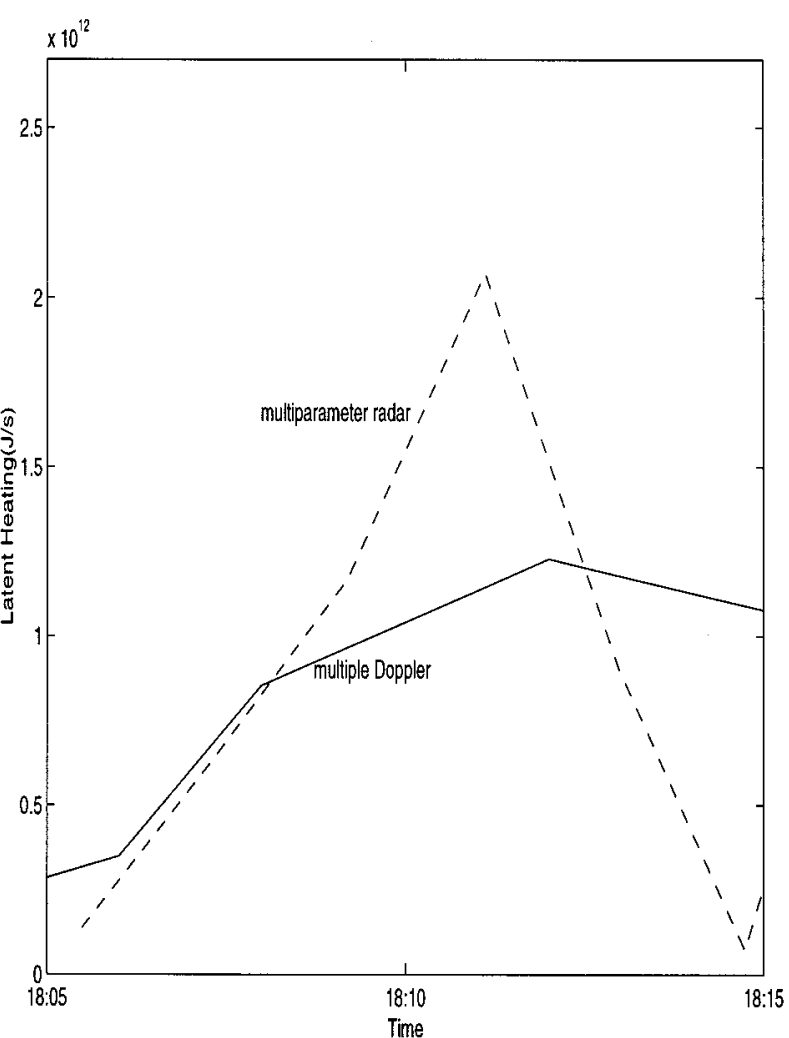

FIG. 10. Time series of latent heating rates from the multiple Doppler analysis on 9 Aug 1991.

\section{a. Standard error of $Z_{\mathrm{DP}}$ signal}

In the following analysis we assume simultaneous sampling to evaluate the standard error in $Z_{\mathrm{DP}}$. We use this primarily to facilitate ease of demonstration, but our analysis can easily be extended to the alternate sampling case. The variance of $P_{\text {diff }}$ can be written as

$$
\operatorname{Var}\left(P_{\text {diff }}\right)=\operatorname{Var}\left(\hat{P}_{\mathrm{H}}\right)+\operatorname{Var}\left(\hat{P}_{\mathrm{V}}\right)-2 \operatorname{Cov}\left(\hat{P}_{\mathrm{H}}, \hat{P}_{\mathrm{V}}\right) ;
$$

$\operatorname{Var}\left(\hat{P}_{\mathrm{H}}\right)$ and $\operatorname{Var}\left(\hat{P}_{\mathrm{V}}\right)$ can be expressed as

$$
\operatorname{Var}\left(\hat{P}_{\mathrm{H}}\right)=\frac{\left(\bar{P}_{\mathrm{H}}\right)^{2}}{M^{2}} \sum_{m=-(M-1)}^{(M-1)}(M-|m|) \rho_{\mathrm{H}}(m)
$$

and

$$
\operatorname{Var}\left(\hat{P}_{\mathrm{V}}\right)=\frac{\left(\bar{P}_{\mathrm{V}}\right)^{2}}{M^{2}} \sum_{m=-(M-1)}^{(M-1)}(M-|m|) \rho_{\mathrm{V}}(m),
$$

where $\bar{P}_{\mathrm{H}}, \bar{P}_{\mathrm{V}}$ are the mean powers at the $\mathrm{H}$ and $\mathrm{V}$ polarizations, respectively, and $\rho_{\mathrm{H}}(m), \rho_{\mathrm{V}}(m)$ are the autocorrelation functions at lag $m$ of power sequences at $\mathrm{H}$ and $\mathrm{V}$ polarizations.

The covariance term in (A6) can be expressed as

$$
\operatorname{Cov}\left(\hat{P}_{\mathrm{H}}, \hat{P}_{\mathrm{V}}\right)=\frac{\bar{P}_{\mathrm{H}} \bar{P}_{\mathrm{V}}}{M^{2}} \sum_{m=-(M-1)}^{(M-1)}(M-|m|) \rho_{\mathrm{HV}}(m) .
$$

Under the assumption that the statistics of horizontally and vertically polarized signals are the same, we can make the assumption $\rho_{\mathrm{H}}(m)=\rho_{\mathrm{V}}(m)=\rho(m)$. Further, we can make the assumption that the decorrelation in polarization and decorrelation in time are due to independent processes, and hence

$$
\rho_{\mathrm{HV}}(m)=\rho(m) \rho_{\mathrm{HV}}(0)
$$

(Sachidananda and Zrnić 1985). Under this assumption, (A9) can be simplified to

$$
\operatorname{Cov}\left(\hat{P}_{\mathrm{H}}, \hat{P}_{\mathrm{V}}\right)=\frac{\bar{P}_{\mathrm{H}} \bar{P}_{\mathrm{V}}}{M^{2}} \rho_{\mathrm{HV}}(0) \sum_{m=-(M-1)}^{(M-1)}(M-|m|) \rho(m) .
$$

Substituting (A7), (A8), and (A11) into (A6), we get

$$
\begin{aligned}
\operatorname{Var}\left(\hat{P}_{\mathrm{H}}-\hat{P}_{\mathrm{V}}\right)= & \frac{1}{M^{2}} \sum_{m=-(M-1)}^{(M-1)}(M-|m|) \rho(m) \\
& \times\left[\bar{P}_{\mathrm{H}}^{2}+\bar{P}_{\mathrm{V}}^{2}-\rho_{\mathrm{HV}}(0) \bar{P}_{\mathrm{H}} \bar{P}_{\mathrm{V}}\right] .
\end{aligned}
$$

Letting

$$
\frac{1}{M^{2}} \sum_{m=-(M-1)}^{(M-1)}(M-|m|) \rho(m)=C,
$$

and with some algebraic manipulations, we get

$$
\begin{aligned}
& \operatorname{Var}\left(\hat{P}_{\mathrm{H}}-\hat{P}_{\mathrm{V}}\right) \\
& \quad=C\left\{\left(\bar{P}_{\mathrm{H}}-\bar{P}_{\mathrm{V}}\right)^{2}+2 \bar{P}_{\mathrm{H}} \bar{P}_{\mathrm{V}}\left[1-\rho_{\mathrm{HV}}(0)\right]\right\} .
\end{aligned}
$$

The normalized variance of $\hat{P}_{\mathrm{H}}-\hat{P}_{\mathrm{V}}$ can be written as

$$
\frac{\operatorname{Var}\left(\hat{P}_{\mathrm{H}}-\hat{P}_{\mathrm{V}}\right)}{\left(\bar{P}_{\mathrm{H}}-\bar{P}_{\mathrm{V}}\right)^{2}}=C\left\{1+\frac{2 \hat{P}_{\mathrm{H}} \bar{P}_{\mathrm{V}}}{\left(\bar{P}_{\mathrm{H}}-\bar{P}_{\mathrm{V}}\right)^{2}}\left[1-\rho_{\mathrm{HV}}(0)\right]\right\} .
$$

The above equation can be simplified to

$$
\begin{aligned}
& \operatorname{FSD}\left(\hat{P}_{\mathrm{H}}-\hat{P}_{\mathrm{V}}\right) \\
& =\sqrt{C}\left\{1+\frac{Z_{\mathrm{DR}}^{\prime}}{\left(Z_{\mathrm{DR}}^{\prime}-1\right)^{2}}\left[1-\rho_{\mathrm{HV}}(0)\right]\right\}^{1 / 2},
\end{aligned}
$$

where FSD is the fractional standard deviation defined as the standard deviation normalized with respect to the mean and $Z_{\mathrm{DR}}^{\prime}$ is conventional $Z_{\mathrm{DR}}$ expressed in a linear scale. The FSD of $\hat{P}_{\mathrm{H}}$ is given by $\operatorname{FSD}\left(\hat{P}_{\mathrm{H}}\right)=\sqrt{C}$. Thus, $\operatorname{FSD}\left(\hat{P}_{\mathrm{H}}-\hat{P}_{\mathrm{V}}\right)$ is nearly the same as $\operatorname{FSD}\left(\hat{P}_{\mathrm{H}}\right)$ except for the additional term involving $\left[1-\rho_{\mathrm{HV}}(0)\right]$. The magnitude of $\rho_{\mathrm{HV}}(0)$ is nearly unity (Sachidananda and Zrnić 1985) for meteorological targets, which implies $\left[1-\rho_{\mathrm{HV}}(0)\right]$ is a small quantity. Thus, we can see that the standard error of $\left(\hat{P}_{\mathrm{H}}-\hat{P}_{\mathrm{V}}\right)$ is nearly the same as that of $\hat{P}_{\mathrm{H}}$, and we can conclude that $Z_{\mathrm{DP}}$ can be estimated to an accuracy nearly the same as $Z_{H}$.

\section{b. Correlation of $Z_{\mathrm{DP}}$ signal with $Z$}

We noted in section 2 that for rainfall, a scattergram between $Z$ and $Z_{\mathrm{DP}}$ falls on a straight line and any de- 
viation from that would be used to identify regions that are not rain. Since we observe such scatterplots in nature, it is useful to understand the correlation between the parameters $Z$ and $Z_{\mathrm{DP}}$.

The correlation $\rho\left(Z, Z_{\mathrm{DP}}\right)$ between $Z$ and $Z_{\mathrm{DP}}$ can be understood by observing the correlation between $\hat{P}_{\mathrm{H}}$ and $\left(\hat{P}_{\mathrm{H}}-\hat{P}_{\mathrm{V}}\right)$ and can be expressed as

$$
\rho\left(Z, Z_{\mathrm{DP}}\right)=\frac{\operatorname{Cov}\left[\left(\hat{P}_{\mathrm{H}}-\hat{P}_{\mathrm{V}}\right), \hat{P}_{\mathrm{H}}\right]}{\left[\operatorname{Var}\left(\hat{P}_{\mathrm{H}}-\hat{P}_{\mathrm{V}}\right) \operatorname{Var}\left(\hat{P}_{\mathrm{H}}\right)\right]^{1 / 2}} .
$$

The numerator can be expanded as

$$
\operatorname{Cov}\left[\left(\hat{P}_{\mathrm{H}}-\hat{P}_{\mathrm{V}}\right), \hat{P}_{\mathrm{H}}\right]=\operatorname{Var}\left(\hat{P}_{\mathrm{H}}\right)-\operatorname{Cov}\left(\hat{P}_{\mathrm{H}}, \hat{P}_{\mathrm{V}}\right) .
$$

The individual terms in (A17) can be expanded using (A7), (A13), and (A14) and with some modest algebraic manipulations we can write

$$
\begin{aligned}
& \rho\left(Z, Z_{\mathrm{DP}}\right) \\
& =\frac{\bar{P}_{\mathrm{H}}^{2}-\bar{P}_{\mathrm{H}} P_{\mathrm{V}} \rho_{\mathrm{HV}}(0)}{\bar{P}_{\mathrm{H}}\left\{\left(\bar{P}_{\mathrm{H}}-\bar{P}_{\mathrm{V}}\right)^{2}+2 \bar{P}_{\mathrm{H}} \bar{P}_{\mathrm{V}}\left[1-\rho_{\mathrm{HV}}(0)\right]\right\}^{1 / 2}} .
\end{aligned}
$$

The above equation can be simplified to

$$
\rho\left(Z, Z_{\mathrm{DP}}\right)=\frac{Z_{\mathrm{DR}}^{\prime}-\rho_{\mathrm{HV}}(0)}{\left\{\left[\left(Z_{\mathrm{DR}}^{\prime}-1\right)^{2}+2 Z_{\mathrm{DR}}^{\prime}\left[1-\rho_{\mathrm{HV}}(0)\right]\right\}^{1 / 2}\right.} .
$$

From the above equation we can see that $\rho\left(Z, Z_{\mathrm{DP}}\right)$ is high for typical meteorological targets. For example, when $Z_{\mathrm{DR}}=2 \mathrm{~dB}$ and $\rho_{\mathrm{HV}}=0.99$, we get $\rho\left(Z, Z_{\mathrm{DP}}\right)=$ 0.97 .

We can see from the results of this section that $Z$ is highly correlated with $Z_{\mathrm{DP}}$ and hence the scatter between $Z$ and $Z_{\mathrm{DP}}$ diagrams are not perturbed by measurement errors. Thus, any deviation from the rain line is significant for the detection of regions that are not pure rain.

\section{REFERENCES}

Aydin, K., T. A. Seliga, and V. Balaji, 1986: Remote sensing of hail with dual linear polarization radar. J. Appl. Meteor., 25, 14751484 .

Balakrishnan, N., and D. S. Zrnić, 1990: Estimation of rain and hail rates in mixed phase precipitation. J. Atmos. Sci., 47, 565-583.

Bringi, V. N., and A. Hendry, 1990: Technology of polarization diversity radars for meteorology. Radar Meteorology, D. Atlas, Ed., Amer. Meteor. Soc., 153-190.

— , R. M. Rasmussen, J. Vivekanandan, and J. D. Tuttle, 1986a: Multiparameter radar measurements in Colorado convective storms. Part I: Graupel melting studies. J. Atmos. Sci., 43, 25452563.

_ $1986 \mathrm{~b}$ : Multiparameter radar measurements in Colorado convective storms. Part II: Hail detection studies. J. Atmos. Sci., 43, 2564-2577.

—, V. Chandrasekar, N. Balakrishnan, and D. S. Zrnić, 1990: An examination of the propagation effects in rainfall on radar measurements at microwave frequencies. J. Atmos. Oceanic Technol., 7, 829-840.

— K. R. Knupp, A. Detwiler, L. Liu, I. J. Caylor, and R. A. Black, 1997: Evolution of a Florida thunderstorm during the Convection and Precipitation Electrification Experiment: The case of $9 \mathrm{Au}-$ gust 1991. Mon. Wea. Rev., 125, 2131-2160.

Chandrasekar, V., C. A. Atwater, and T. H. Vonder Haar, 1991: Convective latent heating estimates from radar data. Preprints, 25th Conf. on Radar Meteorology, Paris, France, Amer. Meteor. Soc., 155-158.

Foote, G. B., 1991: Scientific overview and operations plan for CaPE. NCAR Rep., Boulder, CO, 145 pp.

Golestani, Y., V. Chandrasekar, and V. N. Bringi, 1989: Intercomparison of multiparameter radar measurements. Preprints, 24th Conf. on Radar Meteorology, Tallahasse, FL, Amer. Meteor. Soc., 309-313.

Gorgucci, E., G. Scarchilli, and V. Chandrasekar, 1994: A robust estimator of rainfall rate using differential reflectivity. J. Atmos. Oceanic Technol., 11, 586-592.

Sachidananda, M., and D. S. Zrnić, 1985: $Z_{\mathrm{DR}}$ measurement considerations for a fast scan capability radar. Radio Sci., 20, 907-922.

Seliga, T. A., and V. N. Bringi, 1976: Potential use of radar differential reflectivity measurements at orthogonal polarizations for measuring precipitation. J. Appl. Meteor., 15, 69-76.

Sikdar, P. N., R. E. Schlesinger, and C. E. Anderson, 1974: Severe storm latent heat release. Mon. Wea. Rev., 102, 455-465.

Ulbrich, C. W., 1983: Natural variations in the analytical form of the raindrop size distributions. J. Appl. Meteor., 22, 1764-1775.

Zrnić, D. S., V. N. Bringi, N. Balakrishnan, K. Aydin, V. Chandrasekar, and J. Hubbert, 1993: Polarimetric measurements in a severe hailstorm. Mon. Wea. Rev., 121, 2223-2238. 